\title{
Perbandingan Hasil Belajar Menggunakan Numbered Heads Together dan Structured Numbered Heads dalam Pelajaran Agama
}

\section{Comparison of Religious Learning Results using Numbered Heads Together and Structured Numbered Heads}

\author{
Ignasius Putera Setiahati \\ Universitas Katolik Musi Charitas, Palembang, Sumatera Selatan, Indonesia \\ ig_putra@ukmc.ac.id
}

Naskah diterima tanggal 15/5/2018, Direvisi akhir tanggal 15/7/2018, disetujui tanggal 15/8/2018

\begin{abstract}
Abstrak
Tujuan penelitian ini adalah untuk mengetahui perbedaan hasil belajar menggunakan model pembelajaran numbered heads together dan structured numbered heads dalam Pelajaran Agama di kelas X SMA Xaverius 1 Palembang. Penelitian ini merupakan penelitian eksperimen. Teknik analisis data menggunakan uji homogenitas dan uji hipotesis yaitu independent t-test. Dari hasil tes, nilai rata-rata di kelas eksperimen I menggunakan model pembelajaran numbered heads together adalah 60,71 dan kelas eksperimen II menggunakan model pembelajaran structured numbered heads adalah 81,40. Berdasarkan hasil pengujian menggunakan uji independent sample t-test dengan taraf signifikan $5 \%$, diketahui nilai signifikansi t-hitung adalah $0,000<0,05$ sehingga $H_{0}$ ditolak dan $H_{a}$ diterima. Sehingga diperoleh kesimpulan; 1) ada perbedaan hasil belajar menggunakan model pembelajaran numbered heads together dan structured numbered heads; 2) hasil belajar menggunakan model pembelajaran structured numbered heads lebih baik daripada numbered heads together dalam Pelajaran Agama.

Kata kunci: agama, independent sample t-test, numbered heads together, dan structured numbered heads.
\end{abstract}

\begin{abstract}
The purpose of this research is to know the difference of learning result by using numbered heads together and structured numbered heads learning models in Religious Subject in class $X$ SMA Xaverius 1 Palembang. This research is an experimental research. Data analysis technique using homogeneity and hypothesis tests that is independent t-test. From the test result, the average value in the first experimental class by using numbered heads together learning model is 60.71 and the second experiment class by using the structured numbered heads learning model is 81.40. Based on the test result using independent sample t-test with 5\% significant level, it is known that t-hit significance value is $0,00<0,05$ so $H_{0}$ is rejected and $H_{a}$ is accepted. The conclusion are; 1) there is a difference the learning results using numbered heads together and structured numbered heads in Religious Subject; 2) the results of learning model using structured numbered heads is better than numbered heads together in Religious Subject.
\end{abstract}

Keywords: independent sample t-test, numbered heads together, religious, and structured numbered heads.

\section{PENDAHULUAN}

Beberapa tahun terakhir ini kualitas pendidikan menjadi topik dalam dunia pendidikan khususnya di Indonesia. Ada yang berpendapat bahwa kualitas pendidikan kita yang ada saat ini mengalami penurunan dan belum mampu memenuhi standar sebagaimana diharapkan oleh banyak orang.

Berbagai usaha dilakukan untuk meningkatkan kualitas pendidikan tersebut, antara lain berupa pengembangan kurikulum sebagai keseluruhan program pengalaman belajar, pengadaan buku-buku pelajaran serta buku pegangan guru, penambahan 
wawasan dan penataran guru, dan pembinaan perpustakaan sekolah sebagai pusat sumber belajar. Namun, apapun cara yang telah dilakukan untuk meningkatkan kualitas pendidikan menjadi usaha yang sia-sia tanpa adanya perfoman yang baik dari guru.

Guru menjadi sumber daya manusia yang sangat menentukan keberhasilan program pendidikan. Gurumerupakanunsurmanusiawi yang sangat erat hubungannya dengan anak didik dalam pelaksanaan pendidikan seharihari di sekolah dan banyak menentukan keberhasilan anak didik dalam mencapai tujuan pendidikan (Trianto, 2010; Senen \& Barnadib, 2004; Karaman \& Kurbatova, 2015). Pendidikan yang sesungguhnya harus mampu mendukung pembangunan di masa mendatang dengan cara mengembangkan potensi siswa, sehingga yang bersangkutan mampu menghadapi dan memecahkan masalah kehidupan yang dihadapinya. Pendidikan harus mampu menyentuh potensi nurani maupun potensi kompetensi siswa.

Tentunya, dalam perkembangannya pendidikan tidak lagi bersifat natural instinktif. Maksudnya ialah tidak lagi suatu pola tingkah laku yang diwariskan melalui proses hereditas tetapi proses yang dapat dimanipulasikan untuk mengoptimalkan hasil belajar. Untuk mencapai pada tujuan tersebut tentu saja hal ini tidak terlepas dari faktor-faktor yang mempengaruhi proses belajar mengajar itu sendiri.

Salah satu faktor mempengaruhi proses belajar adalah pemilihan model pembelajaran yang tepat untuk diterapkan di dalam kelas. Faktor-faktor tersebut mendorong berkembangnya pendidikan sebagai ilmu yang sistematis. Menurut UU SISDIKNAS
No 20 tahun 2003, pendidikan adalah usaha sadar dan terencana untuk mewujudkan suasana proses belajar-mengajar agar siswa secara aktif mengembangkan potensi dirinya untuk memiliki kekuatan spiritual keagamaan, pengendalian diri, kepribadian, kedewasaan, akhlak mulia serta keterampilan yang diperlukan dirinya dan masyarakat.

Pada umumnya salah satu pelajaran yang tidak diminati di sekolah adalah pelajaran agama. Dalam memahami pelajaran agama di sekolah, siswa sering mengalami kebosanan dan kurang aktif dalam belajar. Kurangnya keaktifan siswa sangat mempengaruhi hasil belajar siswa. Keberhasilan siswa mempelajari pendidikan agama dapat diukur dari penguasaan, perhatian dan keaktifan siswa. Peranan guru dalam proses pembelajaran sangat penting dalam menentukan keberhasilan siswa, sebab gurulah yang langsung berinteraksi dengan siswa di sekolah. Guru menyampaikan pelajaran agar siswa memahami dengan baik semua pengetahuan yang telah disampaikan itu. Untuk mencapai tujuan tersebut, guru memahami sedalamdalamnya pengetahuan yang menjadi tanggung jawabnya dan menguasai dengan baik model pembelajaran (Hamalik, 2011: 124). Menguasai berbagai macam model pembelajaran sangat menentukan hasil belajar siswa. Masing-masing model pembelajaran mempunyai karekteristik spesifik yang meliputi keunggulan dan keterbatasan untuk digunakan dalam situasi pembelajaran tertentu. Maka perlu memilih model mana yang cocok untuk topic tertentu. Begitu juga model numbered head together dan structured numbered heads mempunyai 
keunggulan dan keterbatasan dalam proses pembelajaran. Maka manarik untuk diteliti.

Model pembelajaran numbered heads together (kepala bernomor) dan structured numbered heads (kepala bernomor terstruktur) yang dikembangkan oleh Russ Frank adalah salah satu model pembelajaran kooperatif yang memberikan kesempatan siswa untuk saling sharing ideide dan mempertimbangkan jawaban yang paling tepat serta meningkatkan semangat kerjasama siswa. Dalam model pembelajaran numbered heads together siswa dibagi dalam kelompok-kelompok. Setiap siswa diberi nomor dan guru memberikan tugas atau pertanyaan dan masing kelompok mengerjakannya (Wahyuni, 2017; Rahman \& Trisnawati, 2015; Apriandi, 2012; Sumarni, 2017; Nurmala, 2016).

Setiap kelompok berdiskusi untuk menemukan jawaban yang diangap paling benar dan memastikan semua anggota mengetahui jawaban tersebut ketika guru memanggil salah satu nomor. Siswa dengan nomor yang dipanggil mempersentasikan jawaban hasil diskusi kelompok mereka. Lain halnya dengan model pembelajaran structured numbered heads, penugasan diberikan kepada siswa berdasarkan nomornya. Sebagai contoh, siswa nomor satu bertugas membaca soal dengan benar dan mengumpulkan data yang berhubungan dengan penyelesaian soal (Nuryana et all., 2017).

Siswa nomor 2 bertugas mencari penyelesaian soal. Siswa nomor 3 mencatat dan melaporkan hasil kerja kelompok. Jika perlu (untuk tugas yang lebih sulit), guru juga bisa melibatkan kerja sama antar kelompok. Siswa diminta keluar dari kelompoknya dan bergabung bersama siswa yang bernomor sama dari kelompok lain. Dengan demikian, siswa dengan tugas yang sama bisa saling membantu atau mencocokan hasil kerja mereka. Dalam banyak kelompok, sering ada anggota yang pasif dan pasrah saja pada rekannya yang lebih dominan. Terkadang dalam situasi seperti ini, pemetaan tanggung jawab dalam kelompok bisa tidak tercapai karena anggota yang pasif akan terlalu menguntungkan dari pada rekannya yang dominan. Maka dari uraian di atas, penulis makin tertarik untuk meneliti tentang perbandingan hasil belajar Agama dengan menggunakan model pembelajaran numbered heads together dan structured numbered heads.

\section{METODE PENELITIAN}

Menurut Arikunto (2010: 160), metode penelitian adalah cara yang digunakan oleh peneliti dalam mengumpulkan data dalam penelitiannya. Berdasarkan pendapat tersebut makametodepenelitianyang digunakan dalam penelitian ini adalah metode eksperimen. Metode eksperimen adalah suatu cara untuk mencari hubungan sebab-akibat (hubungan kasual) antara dua faktor yang ditimbulkan oleh peneliti dengan mengeliminasi, mengurangi atau menyisihkan faktor-faktor lain yang mengganggu (Arikunto, 2010: 9).

Dengan kata lain metode eksperimen selalu dilakukan dengan maksud untuk melihat akibat dari suatu perlakuan. Dalam penelitian ini peneliti bereksperimen pada dua kelompok yang terdiri dari dua kelas yang berbeda kelas X yaitu kelas X IPS 6 sebagai kelas eksperimen dengan menerapkan model pembelajaran numbered heads together dan kelas X IPS 7 sebagai 
kelas eksperimen yang diterapkan dengan model pembelajaran structured numbered heads di SMA Xaverius 1 Palembang. Baik kelas eksperimen numbered heads together maupun kelas eksperimen structured numbered heads ketika berakhirnya kegiatan belajar-mengajar diadakan evaluasi. Evaluasi yang diberikan ini berupa tes yang berupa 8 soal bentuk essay. Dengan pemberian tes ini maka didapatkan hasil belajar yang dicapai oleh siswa tersebut.

Populasi adalah keseluruhan subjek penelitian (Arikunto, 2010:173). Sedangkan menurut Sudjana (2005: 6), populasi adalah totalitas semua nilai yang mungkin, hasil menggukur maupun menghitung, kualitatif maupun kuanitatif mengenai karekteristik tertentu dari semua anggota kumpulan yang lengkap dan jelas yang ingin di pelajari sifatsifatnya. Dalam penelitian ini yang akan dijadikan populasi adalah seluruh siswa kelas $\mathrm{X}$ di SMA Xaverius 1 Palembang Tahun Ajaran 2016/2017 yang terdiri dari 15 kelas yang terdiri dari 8 kelas MIPA dan 7 kelas IPS, dengan jumlah siswa 533 orang.

Menurut Arikunto (2010:174), sampel adalah sebagai atau wakil populasi yang diteliti. Penelitian ini menggunakan teknik sampling probability sampling yaitu teknik pengambilan sampel yang memberikan peluang yang sama bagi setiap unsur (anggota) populasi untuk dipilih menjadi anggota sampel. Teknik pengambilan sampel penelitian ini dilakukan dengan sampel proporsi atau proportional sample atau sampel imbangan.

Sampel yang diambil adalah sebagian atau wakil dari siswa kelas X di SMA Xaverius 1 Palembang. Sampel penelitian berjumlah dua kelas yaitu X IPS 6 berjumlah 21 orang dan X IPS 7 berjumlah 20 orang.

\section{HASIL DAN PEMBAHASAN}

\subsection{Hasil}

Berdasarkan hasil tes homogenitas pada tabel 1 dapat disimpulkan sampel yang diambil homogen kerena $p$-value $=0,844>0,05$ maka data diambil dari sampel yang homogeny.

Tabel 1. Hasil uji homogenitas

\begin{tabular}{lcccc}
\hline Levene Statistic & & df1 & df2 & Sig. \\
\hline .039 & 1 & 39 & .844 \\
\hline
\end{tabular}

Uji validitas dilakukan terhadap soal posttest yang berjumlah 8 soal seperti pada tabel 2 . Berdasarkan output di atas diketahui angka $r_{\text {hitung }}$ untuk item 1 sebesar 0,019, item 2 sebesar 0,527, item 3 sebesar 0,239, item 4 sebesar 0,455, item 5 sebesar 0,462, item 6 sebesar 0,489, item 7 sebesar 0,654, dan item 8 sebesar 0,674 . Langkah selanjutnya mencari nilai $r_{\text {tabel }}$ dengan $\mathrm{N}=41$ dengan df $=39$ pada signifikansi $5 \%$ ditemukan $r_{\text {tabel }}=$ 0,300 . Berdasarkan data yang diperoleh dapat disimpulkan bahwa seluruh soal tersebut valid.

Tabel 2. Hasil uji validasi

\begin{tabular}{cccc}
\hline $\begin{array}{c}\text { Nomor } \\
\text { Item }\end{array}$ & $r_{\boldsymbol{y}}$ & $r_{\text {tabel }}$ & Keterangan \\
\hline 1 & 0,319 & 0,308 & Valid \\
\hline 2 & 0,527 & 0,308 & Valid \\
\hline 3 & 0,339 & 0,308 & Valid \\
\hline 4 & 0,455 & 0,308 & Valid \\
\hline 5 & 0,462 & 0,308 & Valid \\
\hline 6 & 0,489 & 0,308 & Valid \\
\hline 7 & 0,654 & 0,308 & Valid \\
\hline 8 & 0,674 & 0,308 & Valid \\
\hline
\end{tabular}

Berdasarkan tabel di atas diperoleh data bahwa alpha 0,482 kemudian nilai ini dibandingkan dengan nilai $r_{\text {tabel }}$ dengan nilai $\mathrm{N}=41$ dan signifikansi 5\% diperoleh 
nilai $r_{\text {tabel }}=0,444$. Kesimpulan alpha 0,482 $>0,444$ artinya data tersebut reliabel seperti pada tabel 3 .

Tabel 3. Hasil uji reliabilitas

\begin{tabular}{|c|c|}
\hline Cronbach's Alpha & $\mathrm{N}$ of Items \\
\hline .482 & 8 \\
\hline
\end{tabular}

Berdasarkan hasil analisis statistik
independent sample t-test. Dengan menggunakan taraf signifikan 5\%, diperoleh nilai $t_{\text {hitung }}$ adalah 0,000 sedangkan $t_{\text {tabel }}$ adalah 0,05 . Artinya $t_{\text {hitung }}<t_{\text {tabel }}$ sehingga $H_{0}$ ditolak dan $H_{a}$ diterima. Berdasarkan kriteria tersebut disimpulkan ada perbedaan hasil belajar agama yang menggunakan model pembelajaran numbered heads together di kelas X IPS 6 dan model pembelajaran structured numbered heads di kelas X IPS 7.

Nilai rata-rata (mean) pada tes akhir (posttest) lebih besar dari tes awal (pretest) yaitu nilai rata-rata pretest kelas X IPS 6 adalah 53,02 dan kelas X IPS 7 adalah 71,30 sedangkan nilai tes akhir (posttest) kelas $\mathrm{X}$ IPS 6 adalah 60,71 dan kelas X IPS 7 adalah 81,40 .

\subsection{Pembahasan}

Pretest merupakan tes awal yang diberikan kepada siswa untuk mengukur pengetahuan awal siswa. Pada tahap ini peneliti, memberikan tes soal esai berjumlah 8 soal kepada siswa di kelas X IPS 6 dan X IPS 7

\section{Langkah-langkah Numbered Head Together}

Siswa dibagi dalam kelompok, setiap siswa dalam kelompok mendapatkan nomor. Dimana pembagian kelompok menggunakan sistem undi melalui teknik pengambilan nomor di mana peneliti membuat nomor 1 4 dan ada 1 kelompok yang lebih dari 4 orang karena jumlah siswa dalam 1 kelas 21 orang (formasi kelompok: A1-A4, B1-B4, C1-C4, D1-D4, E1-E5). Lalu, siswa duduk dalam kelompoknya masing-masing.

Sementara itu, guru memberikan tugas dan masing-masing kelompok mengerjakannya. Sebaiknya sebelum pemberian tugas guru terlebih dahulu memastikan setiap kelompok memiliki sumber informasi yang relevan seperti buku paket/modul, akses internet, dan lainnya yang dapat memudahkan siswa dalam menyelesaikan tugas yang berikan guru. Pemberian tugas dengan kriteria berikut: Kelompok A1, B1, C1, D1, dan E1 bertugas mengumpulkan data tentang materi yang akan dicari (materi ditentukan oleh peneliti). Kelompok A2, B2, C2, D2, dan E2 bertugas mencatat hasil kerja kelompok. Kelompok A3, B3, C3, D3, dan E3 bertugas melaporkan hasil kerja kelompok. Kelompok A4, B4, C4, D4, dan E4 bertugas menemukan jawaban dari pertanyaan dalam diskusi kelompok. Kelompok A5, B5, C5, D5, dan E5 bertugas mencari berbagai kasus dalam kehidupan nyata terkait dengan materi yang diteliti.

Kelompok mendiskusikan jawaban yang benar dan memastikan tiap kelompok dapat mengerjakan. Guru memperhatikan masingmasing siswa dalam kelompoknya berpikir bersama dalam usaha menemukan jawaban yang tepat atas tugas yang diberikan peneliti serta berusaha meyakinkan bahwa masingmasing anggota kelompok mengetahui jawaban (jika jawabannya sudah berhasil ditemukan kelompok tersebut) dari pertanyaan yang diberikan guru.

Guru memanggil salah satu nomor siswa dan bagi siswa yang nomor dipanggil dari setiap kelompok mengangkat tangan dan melaporkan hasil kerja masing-masing 
kelompoknya kepada seluruh siswa di depan kelas dengan nomor yang dipanggil melaporkan hasil kerja sama mereka.

Siswa yang nomornya tidak disebut guru berusaha memberikan tanggapan atas jawaban dari siswa yang menyampaikan hasil kerja kelompoknya, jika sudah selesai peneliti dapat menunjuk nomor berikutnya. Selanjutnya, guru meminta setiap kelompok untuk membuat kesimpulan dengan cara memanggil nomor lalu guru dan siswa samasama menyimpulkan jawaban akhir yang benar dari setiap pertanyaan yang terkait dengan materi yang telah dibahas

\section{Langkah-langkah Structured Numbered Heads}

Siswa dibagi menjadi empat kelompok yang beranggotakan lima orang siswa dengan karakteristik yang heterogen. Pembagian kelompok dapat juga didasarkan atas kesenangan berteman atau kesamaan tempat duduk, dll.

Masing-masing siswa dalam kelompok diberi nomor urut dengan kriteria pembagian kelompok menggunakan sistem undi melalui teknik pengambilan nomor dimana peneliti membuat nomor 1-4 (formasi kelompok: A1-A4, B1-B4, C1-C4, D1-D4, E1-E4).

Penugasan diberikan kepada siswa berdasarkan nomor urutnya dengan kriteria sebagai berikut: Kelompok 1 (A1, B1, C1, D1, dan E1) bertugas mengumpulkan data tentang materi yang akan dicari. Kelompok 2 (A2, B2, C2, D2, dan E2) bertugas mencatat hasil kerja kelompok. Kelompok 3 (A3, B3, C3, D3, dan E3) bertugas melaporkan hasil kerja kelompok. Kelompok 4 (A4, B4, C4, D4, dan E4) bertugas menemukan jawaban dari pertanyaan dalam diskusi kelompok.
Kelompok 4 (A4, B4, C4, D4, dan E4) bertugas mencari berbagai kasus dalam kehidupan nyata terkait dengan materi yang diteliti

Selanjutnya guru membagikan tugas kelompok kepada siswa dan menyuruh siswa kerjasama antar kelompok jika hal tersebut dipandang perlu, adapun teknisnya adalah siswa disuruh keluar dari kelompoknya dan bergabung bersama beberapa siswa yang memiliki nomor yang sama dari kelompok lain. Pada kesempatan ini, siswa dengan tugas yang sama diberikan keleluasaan untuk dapat saling membantu atau mencocokkan hasil kerjasama yang telah mereka lakukan dan melaporkan hasil kerja kelompok dan pemberian tanggapan dari kelompok lain dan guru memandu dan mengarahkan jalannya diskusi antar kelompok.

Pada pertemuan selanjutnya dalam menggunakan kooperatif tipe SNH, kelompok diskusi tetap pada kelompok yang telah dibentuk pada pertemuan sebelumnya. Guru dapat memutar nomor urut siswa agar siswa tidak jenuh dengan tugas yang siswa dapatkan. Pada tahap akhir siswa menyimpulkan hasil pembelajaran yang telah berlangsung. Peneliti/guru melanjutkan materi yang telah disampaikan pada pertemuan pertama yaitu tentang dampak teknologi (media sosial dan media elektronik) terhadap remaja.

\section{KESIMPULAN}

Berdasarkan hasil penelitian yang telah dilakukan, maka dapat ditarik kesimpulan bahwa ada perbedaan hasil belajar siswa yang menggunakan model pembelajaran numbered heads together dangan hasil belajar siswa yang menggunakan model 
pembelajaran structured numbered heads pada mata pelajaran agama di SMA Xaverius 1 Palembang. Berdasarkan kriteria pengujian hipotesis yaitu $t_{\text {hitung }}<t_{\text {tabel }}$. Dimana nilai $t_{\text {hitung }}$ sebesar 0,000 sedangkan $t_{\text {tabel }}$ 0,05 dengan demikian $H_{0}$ ditolak dan $H_{a}$ diterima.

Berarti "Ada perbedaan hasil belajar agama yang menggunakan model pembelajaran numbered heads together dan model pembelajaran structured numbered heads di kelas X SMA Xaverius 1 Palembang". Berdasarkan hasil nilai rata-rata yang diperoleh dari hasil belajar siswa pada kelas eksperimen I (X IPS $6=60,71)$, kelas eksperimen II (X IPS $7=81,40$ ) dengan kriteria ketuntasan minimum (KKM) yaitu 70,00 untuk mata pelajaran agama.

\section{DAFTAR PUSTAKA}

Apriandi, D. (2012). Efektivitas Model Pembelajaran Kooperatif Tipe Two Stay-Two Stray (Ts-Ts) dan Numbered Heads Together (Nht) Terhadap Prestasi Belajar Matematika Siswa Kelas VIII SMP di Kabupaten Bantul Ditinjau dari Aktivitas Belajar. Jurnal Ilmiah Pendidikan Matematika, 1(1)

Arikunto, S. (2010). Prosedur Penelitian. Jakarta: Rineka Cipta.

Hamalik, O. (2011). Proses Belajar Mengajar. Jakarta: Bumi Aksara.

Karaman, E. L., \& Kurbatova, A. S. (2015). Humanistic aspects of training of social teachers. Вестник Мининского университета, $0(4)$

Nurmala. (2016). Upaya Meningkatkan Hasil Belajar IPS Melalui Penerapan Model Pembelajaran Numbered Head Together (NHT) Siswa Kelas IX.5 SMP Negeri 2 Metro Tahun Pelajaran 2012/2013. Jurnal Promosi Program Studi Pendidikan Ekonomi, 4(1)

Nuryana, I., Widhiastuti, R., \& Murniawaty, I. (2017). Increasing student's character values by utilizing combination of team accelerated instruction and numbered heads together. Dinamika Pendidikan, 11(1):75-86

Rahman, R., \& Trisnawati, W. (2015). Perbedaan Kemampuan Pemecahan Masalah Matematik Siswa yang Mengikuti Pembelajaran dengan Metode Numbered Heads Together dan Metode Konvensional. Infinity, 4(1):96-104

Senen, A., \& Barnadib, I. (2004). Tantangan Guru Sejarah: Pesan Sejarah sebagai Konsep Pendidikan Nilai. Jurnal Penelitian dan Evaluasi Pendidikan, 2(3)

Sudjana. (2005). Metode Statistik. Bandung: Tarsito.

Sumarni. (2017). Upaya Meningkatkan Kemampuan Berhitung Melalui Penerapan Model Pembelajaran Numbered Heads Together dengan Pemanfaatan Alat Peraga Sederhana Materi Pembagian Siswa Kelas II. Refleksi Edukatika, 7(1):58-68

Trianto. (2010). Model Pembelajaran Inovatif-Progresif. Jakarta: Kencana Prenanda Media Group.

Wahyuni, E. T. (2017). Peningkatan Hasil Belajar PKn Materi Organisasi melalui Model Numbered Head Together di Kelas V. Briliant, 2(4):494-503 